\title{
6-Methyluracil derivatives as acetylcholinesterase inhibitors for treatment of Alzheimer's disease
}

\author{
I.V. Zuevaa,b,*, V.E. Semenov ${ }^{\mathrm{a}}$, M.A. Mukhamedyarov' , S.V. Lushchekina ${ }^{\mathrm{a}, \mathrm{d}}$, A.D. Kharlamova ${ }^{\mathrm{a}}$, \\ E.O. Petukhova ${ }^{c}$, A.S. Mikhailov ${ }^{a}$, S.N. Podyachev ${ }^{a}$, L.F. Saifina ${ }^{a}$, K.A. Petrov ${ }^{\mathrm{a}, \mathrm{b}, \mathrm{e}}$, O.A. Minnekhanova ${ }^{\mathrm{a}}$, \\ V.V. Zobov ${ }^{\mathrm{a}, \mathrm{b}}$, E.E. Nikolsky $\mathrm{y}^{\mathrm{a}, \mathrm{b}, \mathrm{c}, \mathrm{e}}$, P. Masson ${ }^{\mathrm{b}}$ and V.S. Reznik ${ }^{\mathrm{a}}$ \\ ${ }^{\mathrm{a}}$ A.E. Arbuzov Institute of Organic and Physical Chemistry, Kazan, Russia \\ ${ }^{\mathrm{b}}$ Kazan Federal University, Kazan, Russia \\ ${ }^{\mathrm{c}}$ Kazan State Medical University, Kazan, Russia \\ ${ }^{\mathrm{d} N}$.M.Emanuel Institute of Biochemical Physics,Moscow, Russia \\ ${ }^{\mathrm{e}}$ Kazan Institute of Biochemistry and Biophysics, Kazan, Russia
}

*Corresponding author. E-mail: zueva.irina.vladimirovna@gmail.com

BACKGROUND: Alzheimer's disease (AD) is the major age-related progressive neurodegenerative disorder. The brain of AD patients suffers from loss of cholinergic neurons and decreased number of synapses [1]. AD is caused by an imbalance between $A \beta$ production and clearance, resulting in increased amount of $A \beta$ in various forms [2]. Reduction of $A \beta$ production and increasing clearance of $A \beta$ pathogenic forms are key targets in the development of potential therapeutic agents for AD treatment. Unfortunately, only nosotropic approaches for treatment of AD are currently effective in humans. These approaches mainly focus on the inhibition of brain acetyl-cholinesterase (AChE) to increase lifetime of cerebral acetylcholine [3]. It is important to emphasize that $\mathrm{AChE}$ itself promotes the formation of $\mathrm{A} \beta$ fibrils in vitro and $\mathrm{A} \beta$ plaques in the cerebral cortex of transgenic mouse models of $\mathrm{AD}$ [4]. This property of $A C h E$ results from interaction between $A \beta$ and the peripheral anionic site of the enzyme (PAS) [5]. Dual binding site inhibitors of both catalytic active site (CAS) and PAS can simultaneously improve cognition and slow down the rate of $\mathrm{A} \beta$-induced neural degeneration. Unfortunately, the assortment of AChE PAS ligands is still extremely limited.

OBJECTIVE: To study putative advantages of AChE non-charged PAS inhibitors based on 6-methyluracil derivatives for the treatment of Alzheimer's disease.

\section{METHODS:}

In vitro studies. Concentration of drug producing $50 \%$ of $\mathrm{AChE} / \mathrm{BuChE}$ activity inhibition (IC50) was measured using the method of Ellman et al. [6]. Toxicological experiments were performed using IP injection of the different compounds in mice. LD50, dose (in $\mathrm{mg} / \mathrm{kg}$ ) causing lethal effects in $50 \%$ of animals was taken as a criterion of toxicity [7]. The ability of compound to block in vitro AChE-induced A $\beta 1-40$ aggregation was studied using a thioflavin T (ThT) fluorescent probe [8].

In vivo biological assays. For in vivo blood-brain barrier permeation assay brains were removed 30 min after IP injection of LD50 dose of tested compound injection. The inhibitory potency was measured using the method of Ellman. 
Scopolamine and transgenic models of AD were used to evaluate the influence of compound 35 on spatial memory performance. Water solution of scopolamine was injected to mice (ip) 20 minutes before starting memory test during 14 days [9]. Mice were assigned to 7 groups, including 4 groups receiving injection (ip) of compound in different dosages, donepezil-treated mice (donepezil is conventionally used to treat Alzheimer's disease), positive and negative control groups. Double transgenic (APP/PS1) mice expressing a chimeric mouse/human amyloid precursor protein and a mutant of human presenilin-1 [10] were assigned to 4 groups, including transgenic animals injected (ip) with compound 35 or donepezil solution, positive (transgenes injected with water) and negative (wild-type mice) controls.

To evaluate spatial memory performance, mice were trained on a reward alternation task using a conventional T-maze [11]. The criterion for a mouse having learned the rewarded alternation task was 3 consecutive days of at least 5 correct responses out of the 6 free trials.

For $\beta$-amyloid peptide load was evaluated quantitatively as a number and summary area of Thioflavine $\mathrm{S}$ fluorescent spots in cerebral cortex and hippocampal images using Image J program. Statistical analyses were performed using the Mann-Whitney test.

RESULTS: We evaluated the acute toxicity of the most active compounds. The most potent AChE inhibitor compound $35(\mathrm{IC} 50(\mathrm{AChE})=5 \pm 0.5 \mathrm{nM})$ exhibited the lowest LD50 values $(51 \mathrm{mg} / \mathrm{kg})$ and inhibited brain AChE by more than $71 \pm 1 \%$. Compound 35 at $10 \mathrm{nM}$, exhibited a significant $(35 \pm 9 \%)$ inhibitory activity toward human AChE-induced $\mathrm{A} \beta$ aggregation.

Scopolamine injection induced significant decrease in correct choice percentage in T-maze, as well as decrease in percentage of mice reaching criterion for learning the task by day 14 . This memory deficit was relieved to some extent either by compound $35(5 \mathrm{mg} / \mathrm{kg})$ or donepezil (reference compound) treatment $(0.75 \mathrm{mg} / \mathrm{kg})$. Interestingly, higher doses of compound $35(10$ and $15 \mathrm{mg} / \mathrm{kg})$ produced less therapeutic effect on spatial memory deficit.

Group of APP/PS1 mice showed 3 times lower percentage of reaching behavioral criterion and lower percentage of correct choice in T-maze alternation task comparing to WT mice, whereas compound 35 $(5 \mathrm{mg} / \mathrm{kg})$ or Donepezil treatment effectively improved these parameters in APP/PS1 mice.

Compound 35 treatment $(5 \mathrm{mg} / \mathrm{kg})$ during 14 days significantly reduced percentage of summary area and number of $\beta$-amyloid peptide ( $\beta A P$ ) deposits visualized in sections of cerebral cortex, dentate gyrus, and hippocampal CA3 area in APP/PS1 mice. The most prominent reduction of $\beta$ AP load by compound 35 treatment was found in CA3 area and cerebral cortex. Meanwhile, Donepezil treatment $(1 \mathrm{mg} / \mathrm{kg})$ during 14 days significantly reduced $\beta A P$ load in cerebral cortex but not in dentate gyrus and CA 3 area.

CONCLUSIONS: Experiments showed that the most potent AChE inhibitor compound 35 (6-methyluracil derivative) permeated the blood-brain barrier, improved working memory in the APP/ PS1 transgenic mice and significantly reduced the number and area of $A \beta$ plaques in the brain. Thus, compound 35 is a promising candidate as a bi-functional inhibitor of AChE for treatment of AD.

Keywords: Alzheimer's disease, acetyl-cholinesterase inhibitors, methyluracil derivatives

Conflict of interest statement: Authors declare no conflict of interests.

\section{References}

[1] Davies P, Maloney AJ. Selective loss of central cholinergic neurons in Alzheimer's disease. Lancet. 1976;2(8000):1403. doi: http://dx.doi.org/10.1016/S0140-6736(76)91936-X

[2] Cummings JL. Alzheimer's disease. N. Engl. J. Med. 2004; 351: 56-67. doi: 10.1056/NEJMra040223

[3] Citron M. Alzheimer's disease: Strategies for disease modification. Nat Rev Drug Discov. 2010;9(5):387-98. doi: 10.1038/ $\operatorname{nrd} 2896$ 
[4] Inestrosa NC1, Dinamarca MC, Alvarez A. Amyloid-cholinesterase interactions. Implications for Alzheimer's disease. FEBS J. 2008;275(4):625-32. doi: 10.1111/j.1742-4658.2007.06238.x. Epub 2008 Jan 17.

[5] De Ferrari GV, Canales MA, Shin I, Weiner LM, Silman I, Inestrosa NC. A structural motif of acetylcholinesterase that promotes amyloid beta-peptide fibril formation. Biochemistry. 2001;40(35):10447-57. doi: 10.1021/bi0101392

[6] Ellman GL, Courtney KD, Andres V Jr, Feather-stone RM. Anew and rapid colometric determination of acetylcholinesterase activity. Biochem Pharmacol. 1961;7:88-95.

[7] Weiss ES. An abridged table of probits for use in the graphic solution of the dosage-effect curve. Am J Public Health Nations Health. 1948;38(1 Pt 1): 22-4.

[8] Viayna E., Sola I., Bartolini M., Simone A. De, Tapia-Rojas C., Serrano F.G., Sabaté R., Juárez-Jiménez J., Pérez B., Luque F.J., Andrisano V., Clos M.V., Inestrosa N.C., Muñoz-Torrero D. Synthesis and multitarget biological profiling of a novel family of rhein derivatives as disease-modifying anti-Alzheimer agents. J Med Chem. 2014;57(6):2549-67. doi: 10.1021/jm401824w. Epub 2014 Mar 10

[9] Smith G. Animal models of Alzheimer's disease: experimental cholinergic denervation. Brain Res. 1988;472(2):103-18.

[10] Savonenko A., Xu G.M., Melnikova T., Morton J.L., Gonzales V., Wong M.P., Price D.L., Tang F., Markowska A.L., Borchelt D.R. Episodic-like memory deficits in the APPswe/PS1dE9 mouse model of Alzheimer's disease: relationships to beta-amyloid deposition and neurotransmitter abnormalities. Neurobiol Dis. 2005;18(3):602-17. doi: 10.1016/j.nbd. 2004.10.022

[11] Deacon RM, Rawlins JN. T-maze alternation in the rodent. Nat Protoc. 2006;1(1):7-12. doi:10.1038/nprot.2006.2 